\title{
Effect of deposition temperature on surface acoustic wave velocity of aluminum nitride films determined by Brillouin spectroscopy
}

\author{
M. B. Assouar \\ Laboratoire de Physique des Milieux Ionisés et Applications, UMR 7040 CNRS, Université \\ Henri-Poincaré Nancy 1, Bld. Des Aiguilletes-BP 239, F-54506 Vandoeuvre-lès-Nancy Cédex, France \\ R. J. Jiménez Riobóo and M. Vila \\ Instituto de Ciencia de Materiales de Madrid (CSIC), Cantoblanco, E-28049 Madrid, Spain \\ P. Alnot \\ Laboratoire de Physique des Milieux Ionisés et Applications, UMR 7040 CNRS, Université \\ Henri-Poincaré Nancy 1, Bld. Des Aiguilletes-BP 239, F-54506 Vandoeuvre-lès-Nancy Cédex, France
}

(Received 6 June 2005; accepted 23 September 2005; published online 3 November 2005)

Brillouin spectroscopy has been used to study the effect of the deposition temperature on the surface acoustic wave (SAW) propagation velocity of aluminum nitride (AlN) films. The results show a dependence of the SAW propagation velocity on the growth temperature of AlN films. The highest value of acoustic velocity was obtained for the film elaborated without heating. Structural characterization of the AlN films synthesized at various deposition temperatures was carried out by $\mathrm{x}$-ray diffraction. These analyses pointed out that the deposition temperature influences the standard deviation of (002) AlN film preferred orientation. The growth temperature clearly influences the acoustical and crystalline properties of AIN thin films. (C) 2005 American Institute of Physics. [DOI: $10.1063 / 1.2121927]$

Aluminum nitride $(\mathrm{AlN})$ has been considered as an attractive thin film piezoelectric material for integrated circuit (IC) compatible surface acoustic wave (SAW) devices. This compatibility requires a deposition process at relatively low temperatures. ${ }^{1}$ Then, the study of acoustical properties of AlN films as a function of deposition temperature becomes crucial to develop AlN films of high crystallinity and acoustical quality. High resolution Brillouin spectroscopy (HRBS) was used in order to obtain information about the surface acoustic waves propagation velocity in AlN films elaborated at different growth temperatures. Even though there are some HRBS works on AlN elastic properties ${ }^{2-7}$ the study of the SAWs properties is still a rarity ${ }^{8}$ and no works about the determination of temperature effects on SAW propagation velocity by Brillouin spectroscopy were carried out.

In this work, $c$-axis oriented aluminum nitride thin films on (100) silicon substrates were deposited by the reactive rf magnetron sputtering technique at various substrate holder temperatures [without heating (WH) up to $400{ }^{\circ} \mathrm{C}$ ] with the same thickness $(1.3 \mu \mathrm{m})$. The aluminum target (purity 99.99\%) diameter was $107 \mathrm{~mm}$ and $6.35 \mathrm{~mm}$ thick. The deposition chamber was pumped down to a base pressure of $1 \times 10^{-7}$ mbar by a turbomolecular pump prior to the introduction of the argon-nitrogen gas mixture for AlN thin film production. The gas discharge mixture was $\mathrm{Ar} / \mathrm{N}_{2}$ and the total pressure was kept constant at $5 \times 10^{-3} \mathrm{mbar}$. The nitrogen percentage in the $\mathrm{Ar} / \mathrm{N}_{2}$ gas mixture was $60 \%$ and the rf power delivered by the rf generator was $170 \mathrm{~W}$. In order to perform a better comparison between the different samples, the deposition time of AlN films was adjusted to obtain $1.3 \mu \mathrm{m}$ thick films for various deposition temperatures.

In order to study the growth thermal conditions on the SAW propagation velocity (from now on SAW velocity),
HRBS was the experimental technique chosen. The experimental set up was already described elsewhere. ${ }^{9}$ It can be summarized as follows: The light source was a 2060 Beamlok Spectra Physics $\mathrm{Ar}^{+}$ion laser provided with an intracavity temperature stabilized single-mode and single-frequency z-lok étalon $\left(\lambda_{0}=514.5 \mathrm{~nm}\right)$. The scattered light was analyzed using a Sandercock-type $3+3$ tandem Fabry-Pérot interferometer. ${ }^{10}$ The incident polarization direction was chosen to be in -plane ( $p$ polarization) while no polarization analysis of the scattered light was made. The typical values for finesse and contrast were 150 and $10^{9}$, respectively.

AlN films are very transparent materials thus making extremely difficult to obtain information of SAWs velocity by means of HRBS. A successful way to enhance the ripple scattering mechanism ${ }^{11}$ is to deposit a very thin metallic film on the transparent sample. ${ }^{812-14}$ It has been shown that the thin metallic film will reproduce the main features of the SAWs of the transparent material, as in the case of AlN and synthetic diamond. ${ }^{8,14}$ A $40 \mathrm{~nm}$ thin $\mathrm{Al}$ film was deposited on each of the different AlN film samples via dc magnetron sputtering. The Brillouin spectroscopy was made for all the samples at backscattering with a sagittal angle of $55^{\circ}$. As far as we were only interested in the temperature evolution of the surface acoustic wave velocity, we only needed to fix one acoustic wave vector and follow its changes. In this case $k h=0.8$ ( $k$ is the scattering wave vector and $h$ the thickness of the Al thin film). All the recorded spectra are of similar quality and the inset in Fig. 1 shows the typical spectrum for a growth temperature of $250{ }^{\circ} \mathrm{C}$, where the Rayleigh mode (SRM) and a higher order Sezawa mode (PSM) can be seen. The SAW propagation velocity can be obtained straightforward from the Brillouin frequency shift $(f)$ : 


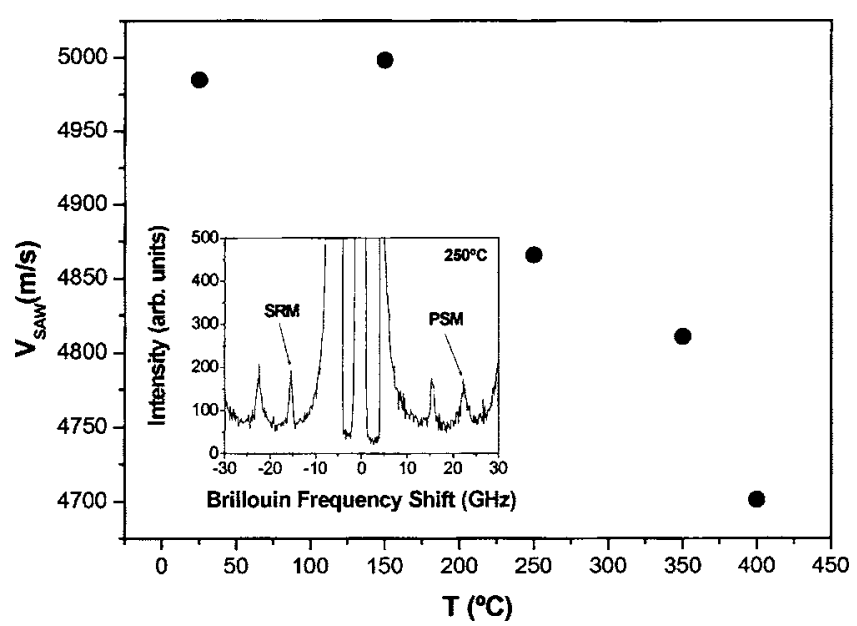

FIG. 1. Growth temperature dependence of the sound propagation velocity of the surface Rayleigh mode. Inset: Brillouin scattering spectrum for the sample growth at $250^{\circ} \mathrm{C}$. The surface Rayleigh mode (SRM) at $15.5 \mathrm{GHz}$ $\left(V_{\mathrm{SAW}}=4867 \mathrm{~m} / \mathrm{s}\right)$ and the Sezawa mode at $22.4 \mathrm{GHz}\left(V_{\mathrm{SAW}}=7037 \mathrm{~m} / \mathrm{s}\right)$ are clearly seen.

$$
V^{\mathrm{SAW}}=\frac{2 \pi f}{q^{\mathrm{SAW}}}=\frac{f \lambda_{0}}{2 \sin (\alpha)} .
$$

$\lambda_{0}$ is the laser wavelength in vacuum, $q^{\mathrm{SAW}}$ the scattering wave vector, and $\alpha$ is the scattering angle (in this case $55^{\circ}$ ). The final results for the different growth temperatures is graphically shown in Fig. 1. The tendency is very clear. The higher the growth temperature the lower the SAW propagation velocity. Only at temperatures near room temperature

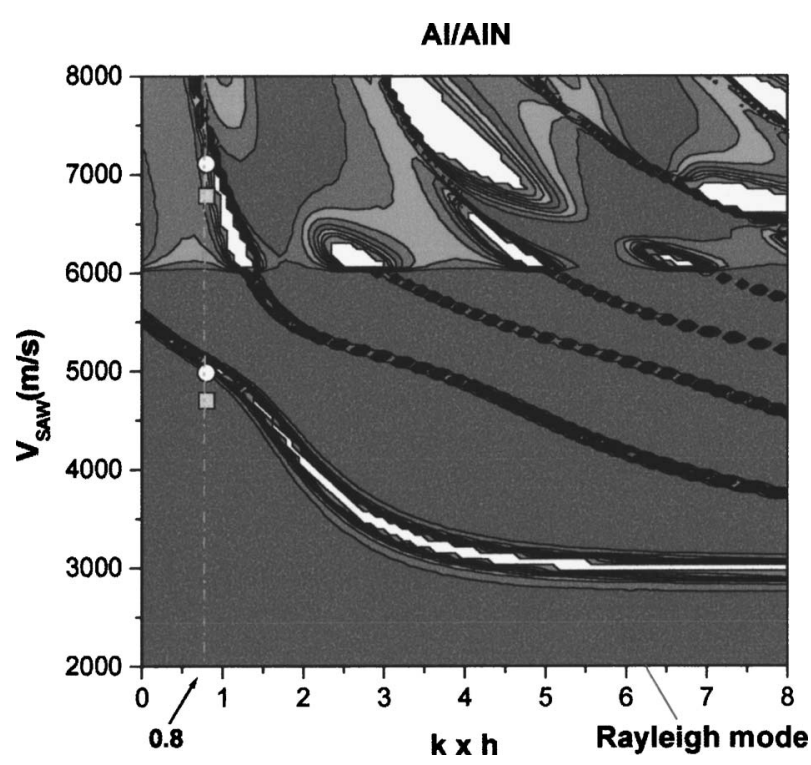

FIG. 2. $k h$ dependence of the propagation velocity of the surface acoustic modes of the Al thin film on AlN film. The AlN elastic constants used for the simulations were those from Ref. 8 and the $\mathrm{Al}$ ones were as follows: $c_{11}$ $=110 \mathrm{GPa} ; c_{44}=27 \mathrm{GPa} ; c_{12}=56.5 \mathrm{GPa}$. The line marks the $k h=0.8$ value. The white circles and the dark squares are the values obtained for samples growth without heating and at $400{ }^{\circ} \mathrm{C}$, respectively. The corresponding sound velocities are $V_{\mathrm{SAW}}=4985 \mathrm{~m} / \mathrm{s}$ for the Rayleigh mode and $V_{\mathrm{SAW}}$ $=7109 \mathrm{~m} / \mathrm{s}$ for the Sezawa mode in the $\mathrm{WH}$ case and are $V_{\mathrm{SAW}}$ $=4701 \mathrm{~m} / \mathrm{s}$ for the Rayleigh mode and $V_{\mathrm{SAW}}=6782 \mathrm{~m} / \mathrm{s}$ for the Sezawa mode in the $400{ }^{\circ} \mathrm{C}$ case. In the case of the WH AlN film the Rayleigh mode shows a very slight difference of about $1.5 \%$ with respect to the value expected in the simulation.

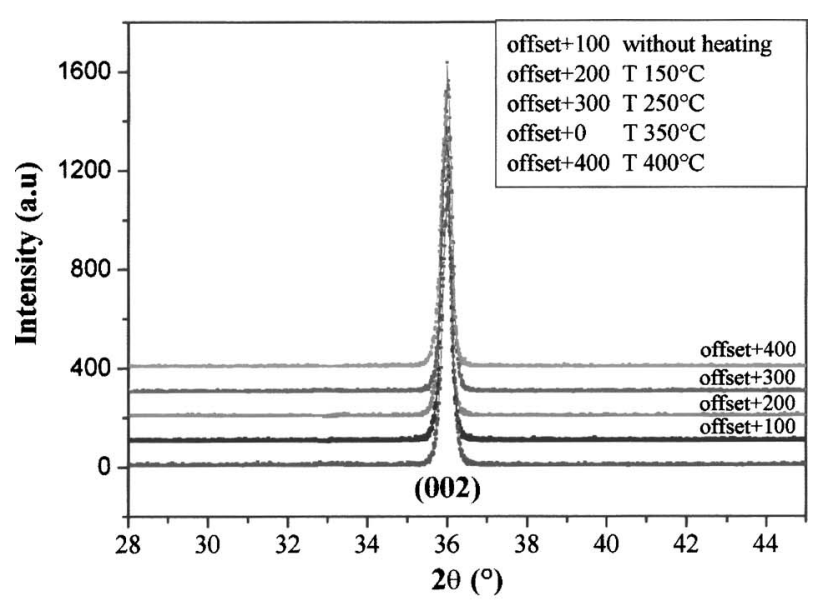

(a)

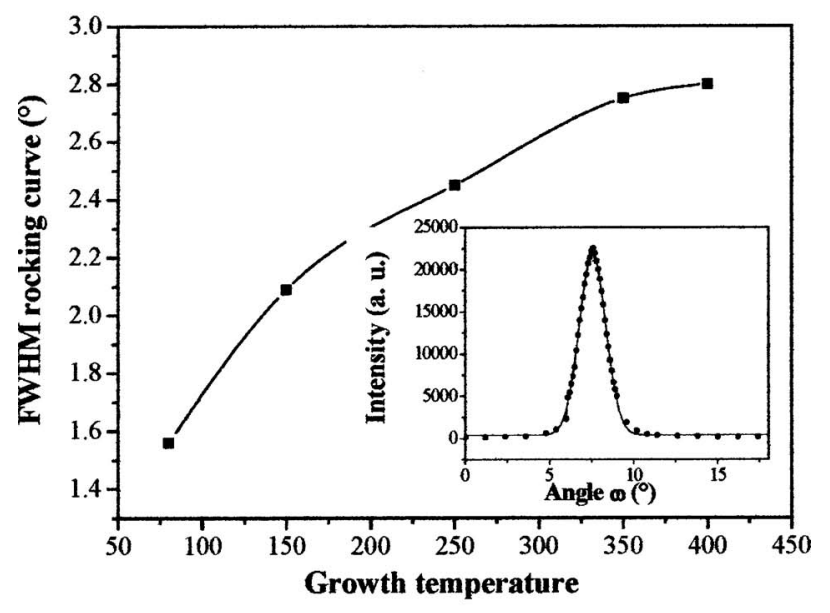

(b)

FIG. 3. (a) XRD pattern of AlN films deposited at various growth temperatures. (b) AlN films $\omega$ rocking curve evolution with growth temperature. The inset shows the rocking curve of AlN film elaborated without heating.

the results do not show significant changes. This differences in sound velocity cannot be due to a possible difference in $\mathrm{Al}$ thin film thickness. All the samples were prepared separately and only stochastic distribution of thickness should be expected. The evolution shown in Fig. 1 clearly discards this effect.

In order to assess the quality of the without heating (WH) sample, a comparison between the SAW velocities obtained by a simulation program ${ }^{15}$ and the experimental results for the two extreme temperature samples has been made and is shown in Fig. 2. From the point of view of the elastic properties the AlN film obtained without heating is of very high quality.

In order to study the origin of the difference in elastic properties, x-ray diffraction (XRD) using $\mathrm{Cu} K \alpha$ cathode was employed to determine the crystalline properties of the AlN thin films. The diffracted intensities were collected in $\theta-2 \theta$ scan and $\omega$ rocking curve scan modes. Figure 3(a) shows the XRD patterns of these films deposited on $\mathrm{Si}(100)$ substrates. We can observe that the preferred orientation of all the films is the (002) orientation corresponding to the $c$ axis perpendicular to the surface. The XRD peak intensities are the same for all the films, which indicate that the growth 


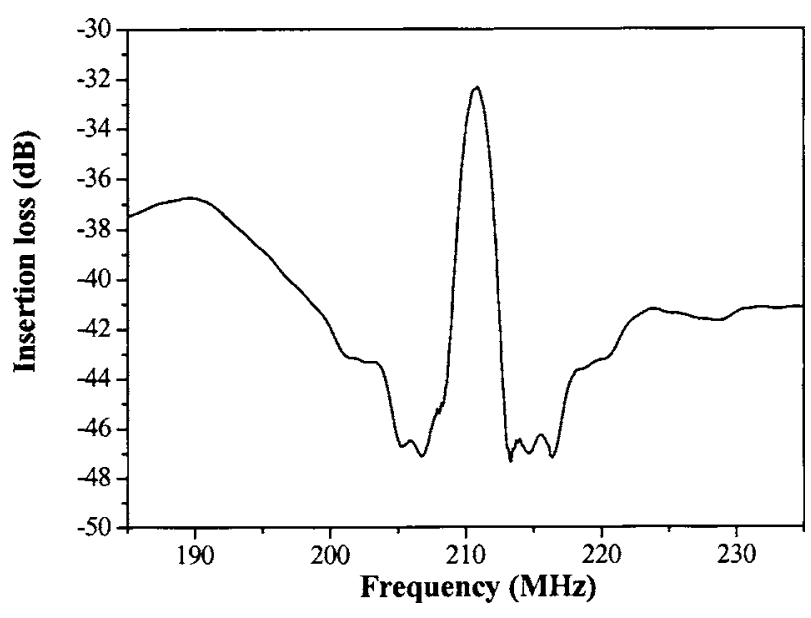

FIG. 4. Frequency response of AIN/Si structure SAW device based on the WH growth film.

temperature does not influence the preferred orientation. However, from the $\omega$ rocking curve scan mode, we have found that the FWHM of the rocking curve of all the AlN films varies from $1.56^{\circ}$ to $2.8^{\circ}$, with the minimum value for the AlN film synthesized without heating. Figure 3(b) exhibits this evolution and as an inset a typical rocking curve obtained for this film. This evolution of crystalline orientation quality can be explained by the possibility of formation of defects in the films at high temperature by promoting the diffusion of impurities into the films introducing structural disorder. ${ }^{16}$ We deduce from these observations that the AlN film synthesized without heating, presents the better crystalline texture. It is obvious that the structural evolution shown by the x-ray analyses should influence the acoustic properties of the samples. An increase of the disorder would imply a decrease in the elastic properties of the material, i.e., the sound propagation velocity, as has been clearly seen in the experimental data of Fig. 1.

The final goal of the AIN films is their application in SAW based devices. ${ }^{17-19}$ To assess the suitability of these films, the one growth without heating was prepared as a SAW device. The SAW transducers were fabricated on the AlN film surface by forming an array of aluminum interdigitated electrodes (IDTs). The thickness of the aluminum layer was $150 \mathrm{~nm}$. It was deposited, patterned, and etched using the UV lithography technique and wet etching. The individual finger widths were $8 \mu \mathrm{m}$ and spacings were $4 \mu \mathrm{m}$. The wavelength of the generated SAW is then $24 \mu \mathrm{m}$. Figure 4 shows the frequency response of the AlN/Si structure SAW device realized using this film. The represented response exhibits the fundamental harmonic of AlN/Si SAW device, which have a resonance frequency around 210.75 $\mathrm{MHz}$. This frequency corresponds, taking into account the wavelength value of $24 \mu \mathrm{m}$, to a SAW velocity of $5058 \mathrm{~m} / \mathrm{s}$. This result remarks the good crystalline quality of the AIN thin film elaborated without heating and it shows a concordance with the acoustic quality determined by Brillouin spectroscopy.
In conclusion, the substrate holder of the rf reactive magnetron sputtering facility has been warmed up to different temperatures in order to study the influence on the elastic properties of the growth temperature. X-ray texture studies performed on these samples show clearly a decrease of the crystalline quality with increasing growth temperature. The SAW propagation velocity shows a clear temperature dependence with the high value for the film synthesized without heating, indicating the influence of the film texture on the SAW properties of the samples. A SAW device based on the without heating AIN film was performed and exhibited excellent performances.

This work was partially supported by the Spanish Ministery of Education and Science (Project No. MAT-200301880), the autonomous community of Madrid (Project No. 07N/0077/2002), and by a bilateral cooperation between CNRS and CSIC within the frame of the Picasso program (common project Assouar/Jiménez) (France) and Acción Integrada 2004FR0008 (Spain).

${ }^{1}$ H. M. Liaw, and F. S. Hickernell, IEEE Trans. Ultrason. Ferroelectr. Freq. Control 42, 404 (1995).

${ }^{2}$ L. E. McNeil, M. Grimsditch, and R. H. French, J. Am. Ceram. Soc. 76, 1132 (1993).

${ }^{3}$ A. Polian, M. Grimsditch, and I. Grzegory, J. Appl. Phys. 79, 3343 (1996).

${ }^{4}$ Y. Tagaki, M. Ahart, T. Azuhata, T. Sota, K. Suzuki, and S. Nakamura, Physica B 219, 547 (1996).

${ }^{5}$ M. Yamaguchi, T. Yagi, T. Sota, T. Deguchi, K. Shimada, and S. Nakamura, J. Appl. Phys. 85, 8502 (1999).

${ }^{6}$ M. Yamaguchi, T. Yagi, T. Azuhata, T. Sota, K. Suzuki, S. Chichibu, and S. Nakamura, J. Phys.: Condens. Matter 9, 241 (1997).

${ }^{7}$ M. Chirita, R. Sooryakumar, R. Venugopal, J. Wan, and M. R. Melloch, Phys. Rev. B 63, 205302 (2001).

${ }^{8}$ R. J. Jiménez Riobóo, E. Rodríguez-Cañas, M. Vila, C. Prieto, F. Calle, T. Palacios, M. A. Sánchez, F. Omnès, O. Ambacher, B. Assouar, and O. Elmazria, J. Appl. Phys. 92, 6868 (2002).

${ }^{9}$ R. J. Jiménez Riobóo, M. García Hernández, C. Prieto, J. J. Fuentes Gallego, E. Blanco, and M. Ramírez del Solar, J. Appl. Phys. 81, 7739 (1997).

${ }^{10}$ J. R. Sandercock, in Light Scattering in Solids III, edited by M. Cardona and G. Guntherdot (Springer, Berlin, 1982), pp 173-204.

${ }^{11}$ P. Mutti, C. E. Bottani, G. Ghislotti, M. Beghi, G. A. D. Briggs, and J. R. Sandercock, in Advances in Acoustic Microscopy, edited by A. Briggs (Plenum, New York, 1995), Vol. 1, pp. 249-300.

${ }^{12}$ H. Sussner, J. Pelous, M. Schmidt, and R. Vacher, Solid State Commun. 36, 123 (1980).

${ }^{13}$ B. Mröz and S. Mielcarek, J. Phys. D 34, 395 (2001).

${ }^{14}$ R. J. Jiménez Riobóo and M. Belmahi, J. Appl. Phys. 97, 073509 (2005).

${ }^{15}$ A. G. Every, University Witwatersrand in South Africa (private communication); X. Zhang, J. D. Comins, A. G. Every, P. R. Stoddart, W. Pang, and T. E. Derry, Phys. Rev. B 58, 13677 (1998).

${ }^{16}$ M. Penza, M. F. De Riccardis, L. Mirenghi, M. A Taligente, and E. Verona, Thin Solid Films 259, 154 (1995).

${ }^{17}$ M. B. Assouar, O. Elmazria, L. Le Brizoual, and P. Alnot, Diamond Relat. Mater. 11, 413 (2002).

${ }^{18}$ M. Ishihara, T. Nakamura, F. Kokai, and Y. Koga, Diamond Relat. Mater. 11, 408 (2002)

${ }^{19}$ V. Mortet, O. Elmazria, M. Nesladek, M. B. Assouar, G. Vanhoyland, J. D'Haen, M. D'Olieslaeger, and P. Alnot, Appl. Phys. Lett. 81, 1720 (2002). 